\title{
Gender Issues in Academic Hospital Medicine: a National Survey of Hospitalist Leaders
}

\author{
Carrie Herzke' , Joanna Bonsall , Amanda Bentram ${ }^{7}$, Hsin-Chieh Yeh ${ }^{7}$, Ariella Apfel ${ }^{7}$, and \\ Joseph Cofrancesco $\mathrm{Jr}^{7}$
}

'Department of Medicine, Johns Hopkins University School of Medicine, Baltimore, USA, MD; ${ }^{2}$ Emory University School of Medicine, Atlanta, GA, USA.

BACKGROUND: Gender inequities are documented in academic medicine. Within General Internal Medicine (GIM), there are fewer female division directors and first and last authors on publications. With gender parity in US medical school graduates and with Academic Hospital (AH) medicine being a relatively newer discipline, one might postulate that $\mathrm{AH}$ would have less gender inequity. DESIGN: A national survey of AH programs was developed via literature review and expert recommendations. Domains included program and faculty information. Gender of the leader was determined via website or telephone call.

PARTICIPANTS: Leaders of AH programs associated with the American Association of Medical Colleges (AAMC). Programs without a primary teaching hospital or hospitalist program and those not staffed by universityaffiliated physicians were excluded.

MAIN MEASURES: Description and characteristics of leaders and programs including a multivariable analysis of gender of hospitalist leaders and the portion of female faculty.

KEY RESULTS: 59\% response rate (80 of 135); there were no differences between responders/non-responders in NIH funding ( $p=0.12)$, type of institution $(p=0.09)$, geographic region $(p=0.15)$, or year established $(p=0.86)$. Reported number of female and male faculty were approximately equal. $80 \%$ of hospitalist leaders were male; $37 \%$ of male hospitalist leaders were professors, no female leaders were professors. In univariate and multivariate analysis only the number of hospitals staffed was a significant predictor of having a female hospitalist leader. There were no significant predictors of having fewer female faculty.

CONCLUSION: This study demonstrated gender inequality in academic hospital medicine regarding leadership and rank. Though there was equal gender distribution of faculty, among leaders most were men and all "full professors" were men. As diversity benefits the tripartite mission research on methods, initiatives and programs that achieve gender equity in leadership are needed.

KEY WORDS: gender; hospital medicine; hospitalist leadership.

Electronic supplementary material The online version of this article (https://doi.org/10.1007/s11606-019-05527-0) contains supplementary material, which is available to authorized users.

Received July 17, 2019

Accepted October 28, 2019

Published online March 3, 2020
J Gen Intern Med 35(6):1641-6

DOI: $10.1007 /$ s11606-019-05527-0

(c) Society of General Internal Medicine 2020

Introduction. Gender inequity in academic medicine is well documented in the literature ${ }^{1-6}$ including issues related to promotion, ${ }^{3,5}$ publication, ${ }^{1,7}$ and grants. ${ }^{7,8}$ Since at least 2003, women have comprised approximately half of graduating medical student classes. ${ }^{9,10}$ Nonetheless, women account for only $39 \%$ of full-time academic faculty and only $22 \%$ of full professors. ${ }^{9}$ Additionally, women remain significantly underrepresented in hospital leadership positions, comprising only $11 \%$ of hospital CEOs, ${ }^{11} 16 \%$ of Deans, $15 \%$ of department chairs, and $24 \%$ of division directors ${ }^{9,12}$. Other disparities including academic rank, career advancement, leadership opportunities and compensation also persist. ${ }^{1-8,13-16}$

In Academic Medicine, women are under-represented in leadership positions for all specialties. In specialties with fewer female faculty, such as General Surgery, which has $22 \%$ female faculty, only $1.4 \%$ of department chairs are female. Even in specialties with a majority of female faculty, such as Obstetrics and Gynecology and Pediatrics, which have greater than $50 \%$ female faculty, only $22 \%$ of department chairs are female. ${ }^{12}$ Within Departments of Medicine, $9.1 \%$ of chairs, $23.5 \%$ of vice chairs, $16.4 \%$ of division directors, and $27.8 \%$ of program directors are women ${ }^{12}$. Gender issues also exist within GIM. ${ }^{7}$ Compared to men, there are fewer female division directors and first and senior authors of published manuscripts. ${ }^{7}$

Compared to GIM, which held the first meeting of the Society for Research and Education in Primary Care Internal Medicine (the precursor of the Society of General Internal Medicine) in 1978, ${ }^{17}$ Academic Hospital Medicine (AHM) hospitalists working in academic medical centers with patient care, leadership, teaching and research expectations - is a relatively new field that has experienced tremendous growth over the past 20 years. ${ }^{18}$ All academic medical centers in the top quartile of NIH funding and ranked in the top 25 by US News and World Report have a hospitalist program, ${ }^{18,19}$ with an estimated 7000 academic hospitalists in practice (Society of 
Hospital Medicine (SHM) verbal report). As a newer field, one might hypothesize that there would be significantly less gender inequity. However, Burden and colleagues found gender inequity in AHM, which appears more significant than in GIM. ${ }^{7,14,15}$ Women academic hospitalists earn nearly $\$ 15,000$ less than men and have been less represented at national meetings, in leadership, and as first or last authors than their general internist peers. $(7,13)$

While these studies demonstrated gender inequality in AHM, they have not evaluated the impact of program characteristics such as being a separate division or part of GIM, and program leadership on gender issues. There remains debate about the optimal structure of academic hospitalist programs, ${ }^{20}$ the impact of these structures on gender has not been explored.

In association with SHM, we conducted a national survey of all leaders of AHM programs associated with an American Association of Medical Colleges (AAMC) affiliated medical center. In this paper, we focus on gender, specifically the gender and academic rank of AHM leadership, and the effect of the gender of hospitalist program leadership on AHM structure and organization. We explore possible predictors of having a female leader and the proportion of female faculty. For the purpose of this survey we defined academic hospitalist (AH) as a physician whose primary professional focus is the care of general medical hospitalized patients and who works at hospital(s) associated with AAMC and is employed by either the health center or university, modified after Freed and Dunham's definition of academic pediatric hospitalists. ${ }^{21}$

\section{METHODS}

\section{Study Population}

All US medical schools, as listed by the AAMC were selected. For each, the primary teaching hospital as well as the name and contact (email, telephone, and office address) for the hospitalist director (or equivalent), was identified using institutional website listing and internet searches. All intuitions were contacted by telephone or email to confirm the contact information. Institutions were excluded if a primary teaching hospital could not be identified, the associated hospital(s) lacked a hospitalist program, or the primary teaching hospital was staffed by private, external corporations. Veteran's Affairs hospitals were also excluded.

\section{Survey}

After study objectives were refined, the domains for the survey instrument were developed using a review of the literature, discussion with experts and in collaboration with the Academic Committee of SHM. Domains included: gender, respondent program and faculty information, as well as perceptions about promotion and faculty development.

It was piloted for clarity, ease of use, and relevance to academic hospital medicine by 5 academic hospitalist leaders who were not program directors and thus not did not participate in completing the final survey. The survey instrument was designed to be answered by hospitalist leadership and sent electronically using Qualtrics®, with follow-up email and paper reminders to non-responders. The instrument was comprised of a mixture of fixed-choice, Likert-scale, and openended questions. The survey instrument is available in the appendix. This project was acknowledged as exempt by the Johns Hopkins IRB. For this manuscript we focused on survey domains pertinent to issues related to gender.

\section{Statistical Analysis}

Means, standard deviations, medians, interquartile ranges, and proportions were used to describe data distribution. Chi-square tests were used to compare differences between respondents and non-respondents. Comparisons were made between respondents and non-respondents including region of the country (based on regions as predetermined by the Society of General Internal Medicine), NIH funding quartile, private versus public medical school, and years of existence of the associated medical school (less than 10 versus greater than 10 years). All further analyses were performed on the subgroup of responders that identified as Directors of the Hospitalist Program. Chisquare and Fisher's Exact tests were used to test for associations between our outcome (gender of the hospitalist leader) and categorical covariates of interest. Wilcoxon Rank Sum tests were used to test associations between gender of leader and time in role. Tests of significance were two tailed, with an alpha level of 0.05 .

Univariate and Multivariable logistic regression were conducted to predict having a female hospitalist leader and being in the highest quartile of female faculty. The analyses adjusted for academic rank of Hospitalist Director, years in role, NIH funding, being part of division of GIM, number of hospitals the leader is responsible for, organization of the associated medical school (private vs public), time with learners, size of program, percent female faculty, percent of faculty that are professors, associate professors, assistant professors, instructors, whether the institution is multi-track or single track, and whether the associated medical school has been established for greater than or less than 10 years. The multivariable logistic regression model predicting gender of leader included a binary rank of leader (Professor/Associate vs Assistant) variable. The univariate logistic regression model predicting gender by rank used the Firth method. Both of these changes were in order to avoid quasi-complete separation of data points caused by the original rank variable being split over the gender outcome since there were no instances of female professors thus not allowing for a maximum likelihood estimate. Analyses used Stata/SE, v12 and SAS 9.4.

\section{RESULTS}

\section{Response Rates}

146 AAMC programs were identified. Eleven were excluded due to lack of a primary teaching hospital (6), absence of a hospitalist program (1), or employment of hospitalists through 
a staffing company (4). 80 of 135 surveys (59\%) were returned. There were no significant institutional differences between responders and non-responders regarding quartile of NIH funding ( $p=0.12$ ), type of institution (public/private; $p=$ $0.09)$, geographic region $(p=0.15)$, or institutions' year established (more or less than 10 years; $p=0.86$ ).

\section{Program Characteristics}

Table 1 describes the general characteristics of the programs. The number of hospitals each program covered varied. The clinical expectations for 1 FTE was a mean of 30.6 weeks per year (SD 7.52, range 21-48); $2014 \mathrm{~h}$ per year (SD 326.3, Range 728-2400); $59.5 \mathrm{~h}$ per week (SD 17.29, range 2584 ), or 188 shifts per year (SD 188.23, range 170-216). Several programs provide service to specialty services other than general medicine, including oncology, neurology, orthopedic surgery, and pulmonary/stepdown services, either as the primary attending or in a co-management model.

On average, $\mathrm{AH}$ spend $54 \%$ of their clinical time on teaching services at the main teaching hospital. Teaching in the clinical setting also occurs at many of the community hospitals. Of the $46 \%$ of programs who cover community hospitals approximately half $(49 \%)$ of the faculty at those sites have associated teaching responsibilities. 53\% of AHM groups are their own division/ department while $45 \%$ are part of another division.

Leader Characteristics. Of the 80 respondents to the survey $66(82.5 \%)$ described their title as "hospitalist director" or equivalent, 2 described their role as GIM division director (2 male), 5 identified as Internal Medicine Program Directors (5 male), 1 was a faculty member (male), 1 was an administrator (female), and 1 was Chairman of the Department of Medicine (male), 1 was a Vice-Chair of the Department of Medicine (female), 1 identified as the Director of Faculty development (female), 1 respondent's role was listed as other (male) and 1 respondent's role was unknown (male).

Of the 66 academic hospital medicine leaders, nearly $80 \%$ are male. This inequity persisted regardless of whether these programs were in their own department or division (59\%) or part of GIM (41\%). Of the other leaders, 2 were women (GIM Director and Vice Chair of Medicine). (Table 2).

Of the 66 Directors of Hospitalist Programs, 29\% were at the rank of Professor, $36 \%$ were Associate, and 35\% were Assistant Professors (Table 3). None of the full professors were female, despite there being no significant difference in time in their leadership role (median 3.5-4.3 years, $p=0.1657$; Table 3).

Among the 66 programs there were no significant differences between programs with female leaders versus those with male leaders, including size ( $p=.4753)$, quartile of NIH funding $(p=.7449)$, promotion tracks $(p=.2657)$, organization structure (part of GIM versus being a separate department/ division; $p=.6560)$, percentage of female faculty $(p=.7199)$, or type of hospital $(p=.1576)$ based on gender of the hospital leader. (Table 4).
Table 1 Hospitalist Program Characteristics

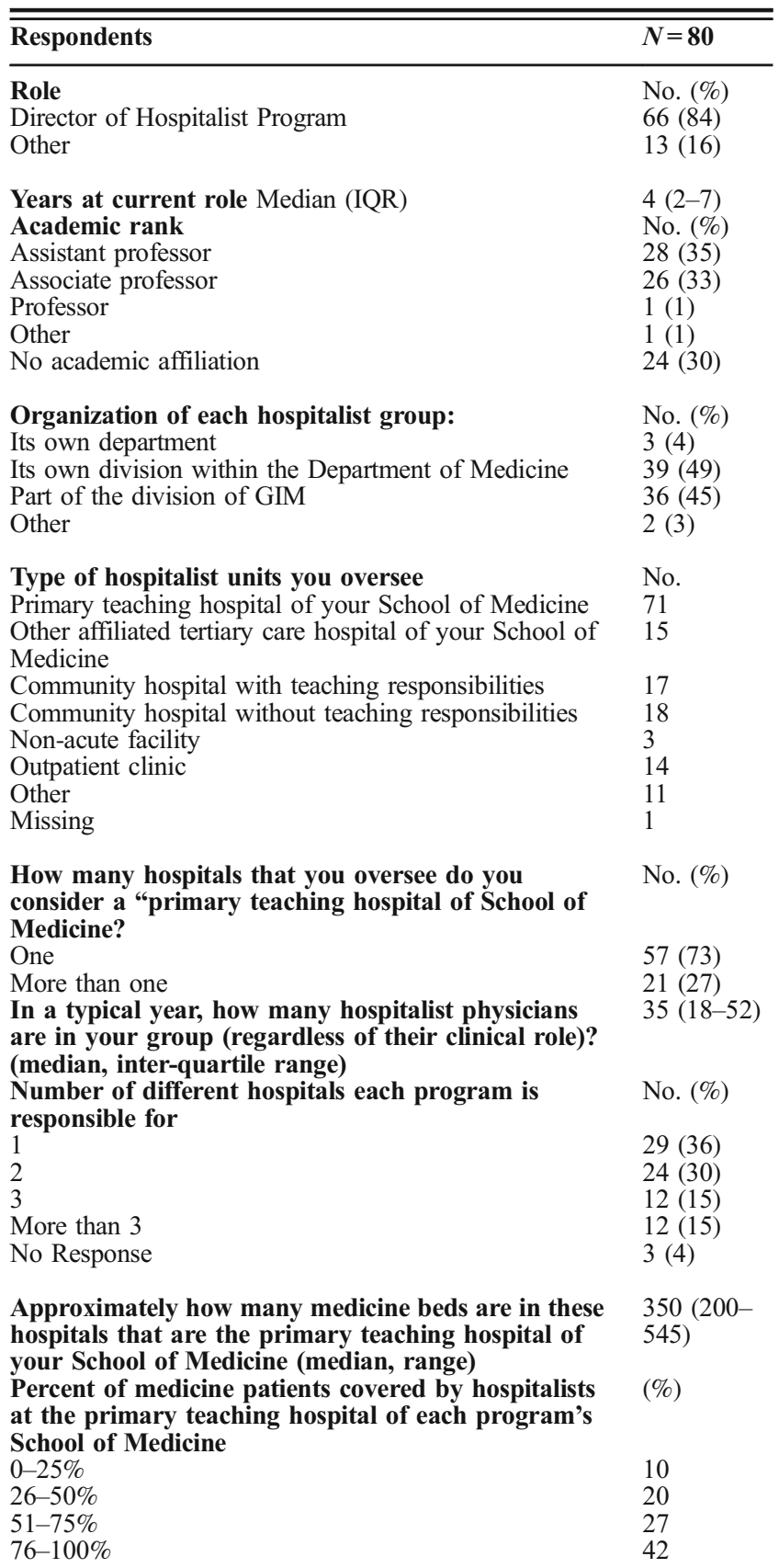

For a typical hospitalist, what percent of clinical time is spent:

With learners Median (IQR)

Without learners Median (IQR)

$50(27-80)$

$50(20-72)$

In a typical year, how many hospitalist physicians are in your group? Median (IQR)

On average, what percentage of your hospitalist physicians are female? Median (IQR)

On average, what percent of your hospitalists stay for 3 or less years:

$<25 \%$

$25-50 \%$

$50-75 \%$

$>75 \%$

35 (18-52)

$50(40-55)$

50 (64)

23 (29)

5 (6)

$0(0)$ 
Table 1. (continued)

\begin{tabular}{ll}
\hline \hline Respondents & $\mathbf{N = 8 0}$ \\
\hline $\begin{array}{l}\text { Please estimate the percent of your hospitalist faculty } \\
\text { that are: }\end{array}$ & \\
$\begin{array}{l}\text { Instructors or equivalent Median (IQR) } \\
\text { Assistant professors or equivalent Median (IQR) }\end{array}$ & $10(0-25)$ \\
$\begin{array}{l}\text { Associate professors or equivalent Median (IQR) } \\
\text { Professors or equivalent Median (IQR) }\end{array}$ & $10(5-20)$ \\
Clinical staff/Clinical associates Median (Range) & $1.5(0-5)$ \\
$\begin{array}{l}\text { Hospitalists without academic appointments Median } \\
\text { (Range) }\end{array}$ & $0(0-100)$ \\
& \\
$\begin{array}{l}\text { Approximately what percentage of your hospitalist } \\
\text { faculty are on a tenure track? Median (IQR)/ N (\%) }\end{array}$ & $0(0-5)$ \\
0 & $50(66)$ \\
$1-10$ & $14(18)$ \\
$11-100$ & $12(16)$ \\
\hline
\end{tabular}

In univariate and multivariate analysis including quartile of NIH funding, being part of GIM versus a separate Department/ Division, number of hospitals staffed, being associated with a private versus public medical school, years in existence of the associated medical school (less than 10 versus more than 10 ), percentage of clinical time with learners, number of hospitalists, percentage of female faculty, academic rank of faculty, promotion tracks (single vs multiple), only the number of hospitals staffed was a significant predictor of having a female hospitalist director. Female leaders were associated with programs that staffed fewer hospitals.

\section{Faculty Characteristics}

Most academic hospitalists have identified hospital medicine as a career, with $64 \%$ of programs reporting more than $75 \%$ of their faculty plan to remain a minimum of 3 years. $47 \%$ of academic hospitalist faculty are female. In univariate and multivariate analysis there were no predictors of having fewer female faculty, including $\mathrm{NIH}$ funding, being part of GIM versus a separate Department/Division, number of hospitals staffed, being

Table 2 Leadership Role and Gender of the Survey Responders

\begin{tabular}{llll}
\hline \hline & $\begin{array}{l}\text { Female N } \\
(\mathbf{\%})\end{array}$ & $\begin{array}{l}\text { Male N } \\
(\mathbf{\%})\end{array}$ & $\begin{array}{l}\text { Total } \\
\mathbf{N}\end{array}$ \\
\hline ALL RESPONDERS & $\mathbf{1 7}(\mathbf{2 1 \% )}$ & $\mathbf{6 3}(\mathbf{7 9 \%})$ & $\mathbf{8 0}$ \\
$\begin{array}{l}\text { Director of Hospitalist } \\
\text { Program }\end{array}$ & $14(21 \%)$ & $52(79 \%)$ & 66 \\
GIM Division & $5(19 \%)$ & $22(81 \%)$ & 27 \\
Own Division within DOM & $9(24 \%)$ & $28(76 \%)$ & 37 \\
Other/Own Department & $0(0 \%)$ & $2(100 \%)$ & 2 \\
Other & $3(23 \%)$ & $10(77 \%)$ & 13 \\
Other Leaders & $2(20 \%)$ & $8(80 \%)$ & 10 \\
Other Non-Leaders & $1(33 \%)$ & $2(67 \%)$ & 3 \\
Unknown Role (missing) & $0(0 \%)$ & $1(100 \%)$ & 1 \\
\hline
\end{tabular}

*Other includes: Chairmen of Medicine (1), Vice Chair (1), Internal medicine program directors (5), Chief of General Internal Medicine (2), Director of Faculty Development (1); Faculty (1) administrator (1), other (1)
Table 3 Hospitalist Director Rank and Years in Role

\begin{tabular}{|c|c|c|c|}
\hline & $\begin{array}{l}\text { Female } \\
(\mathrm{N}=14) \\
\mathbf{N}(\%)\end{array}$ & $\begin{array}{l}\text { Male } \\
(N=52) \\
N(\%)\end{array}$ & $\begin{array}{l}p \\
\text { Value }\end{array}$ \\
\hline \multicolumn{4}{|l|}{ Rank of Hospitalist Leaders } \\
\hline Professor & $0(0 \%)$ & $19(37 \%)$ & 0.0103 \\
\hline Associate Professor & $6(43 \%)$ & $18(35 \%)$ & \\
\hline Assistant Professor & $8(57 \%)$ & $15(29 \%)$ & \\
\hline Hospitalist Leader Years in & $3.5(2-$ & $4.3(2.25-$ & 0.1657 \\
\hline Role / Median (IQR) & 5) & $7.5)$ & \\
\hline
\end{tabular}

associated with a private versus public medical school, years in existence of the associated medical school (less than 10 versus more than 10), percentage of clinical time with learners, number of hospitalists, academic rank of faculty, gender of the hospitalist leader, having a single vs multiple promotion tracks, or percentage of protected time.

\section{DISCUSSION}

Gender inequity in medicine has been well described. As a relatively new field, with roughly equal numbers of men and women graduating from medical school in the past 20 years, we had hoped to find less gender inequity in AHM. Nearly $50 \%$ of academic hospitalist faculty are female. However, our study suggests gender inequality in AHM leadership. Nearly all of the leadership positions were held by men. This supports prior data highlighting gender disparities in leadership within academic hospital medicine. ${ }^{7,14}$ Women in leadership positions in our study were more frequently Assistant Professors and none were Professors, as compared to male leaders, nearly $40 \%$ of whom hold the rank of professor. This, despite there being no significant differences in the time they were in their leadership role. This is consistent with work published by Burden and colleagues ${ }^{7}$ which found that only $16 \%$ of academic divisions or sections of hospital medicine were led by women. Although we do not have the time leaders had been in academic medicine, we use time in a leadership role as a proxy. It may be that the men had been in academia longer, however, as a relatively new field, time in academia would be expected to be similar between males and females and we saw no significant differences between time in leadership roles between males and females.

While there has been discussion about the best structure for academic hospitalist programs ${ }^{20}$, we did not find significant differences in the reported percentage of female faculty between AHM programs that were their own division/ department compared to those who are part of GIM divisions. There was also no difference between numbers of programs with female hospitalist directors for programs which are separate divisions/departments versus being part of GIM. Additionally, we did not find an association of the percent of female faculty with the gender of hospitalist leadership. 
Table 4 Hospitalist Program Characteristics by Gender of Hospitalist Leader

\begin{tabular}{|c|c|c|c|c|}
\hline & $\begin{array}{l}\text { Female Director of Hospitalist } \\
\text { Program }\end{array}$ & $\begin{array}{l}\text { Male Director of Hospitalist } \\
\text { Program }\end{array}$ & Total & $\begin{array}{l}\text { p } \\
\text { Value }\end{array}$ \\
\hline Size of the Program (by quartiles) & $(N=13)$ & $(\mathrm{N}=52)$ & $(N=65)$ & $p_{\text {plue }}$ \\
\hline Q1 (lowest) & $2(15 \%)$ & $9(17 \%)$ & $\begin{array}{l}11 \\
(17 \%)\end{array}$ & 0.4753 \\
\hline Q2 & $3(23 \%)$ & $15(29 \%)$ & $\begin{array}{l}18 \\
(28 \%)\end{array}$ & \\
\hline Q3 & $6(46 \%)$ & $12(23 \%)$ & $\begin{array}{l}18 \\
(28 \%)\end{array}$ & \\
\hline Q4 (highest) & $2(15 \%)$ & $16(31 \%)$ & $\begin{array}{l}18 \\
(28 \%)\end{array}$ & \\
\hline NIH Funding (by quartiles) & $(N=14)$ & $(N=52)$ & $(N=66)$ & $\begin{array}{l}\text { p } \\
\text { Value }\end{array}$ \\
\hline Q1 (lowest) & $5(36 \%)$ & $11(21 \%)$ & $\begin{array}{l}16 \\
(24 \%)\end{array}$ & 0.7449 \\
\hline Q2 & $2(14 \%)$ & $12(23 \%)$ & $\begin{array}{l}14 \\
(21 \%)\end{array}$ & \\
\hline Q3 & $3(21 \%)$ & $14(27 \%)$ & $\begin{array}{l}17 \\
(26 \%)\end{array}$ & \\
\hline Q4 (highest) & $4(29 \%)$ & $15(29 \%)$ & & \\
\hline Promotion Tracks & $(\mathbf{N}=13)$ & $(N=51)$ & $(N=64)$ & $p$ Value \\
\hline Multiple & $12(92 \%)$ & $38(75 \%)$ & $\begin{array}{l}50 \\
(78 \%)\end{array}$ & 0.2657 \\
\hline Single & $1(8 \%)$ & $13(25 \%)$ & $\begin{array}{l}14 \\
(22 \%)\end{array}$ & \\
\hline Organizational Structure & $(N=14)$ & $(\mathrm{N}=52)$ & $(N=66)$ & $\begin{array}{l}p \\
\text { Value }\end{array}$ \\
\hline Hospitalist Program is part of GIM & $5(36 \%)$ & $22(42 \%)$ & $\begin{array}{l}27 \\
(41 \%)\end{array}$ & 0.6560 \\
\hline Hospitalist Program is its Own Division/Other & $9(64 \%)$ & $30(58 \%)$ & & \\
\hline Quartile of female faculty & $(N=14)$ & $(\mathrm{N}=52)$ & $(\mathrm{N}=66)$ & Value \\
\hline Q1 (lowest) & $4(29 \%)$ & $11(21 \%)$ & $\begin{array}{l}15 \\
(23 \%)\end{array}$ & 0.7199 \\
\hline Q2 & $3(21 \%)$ & $13(25 \%)$ & $\begin{array}{l}16 \\
(24 \%)\end{array}$ & \\
\hline Q3 & $2(14 \%)$ & $14(27 \%)$ & $\begin{array}{l}16 \\
(24 \%)\end{array}$ & \\
\hline Q4 (highest) & $5(36 \%)$ & $14(27 \%)$ & $\begin{array}{l}19 \\
(29 \%)\end{array}$ & \\
\hline Type of hospitals Staffed & $(\mathrm{N}=14)$ & $(\mathrm{N}=52)$ & $(\mathrm{N}=66)$ & palue \\
\hline Primary teaching hospital $(0)$ & $9(64 \%)$ & $18(35 \%)$ & 27 & 0.1576 \\
\hline $\begin{array}{l}\text { Primary teaching hospital plus any other } \\
\text { hospital (1) }\end{array}$ & $0(0 \%)$ & $2(4 \%)$ & $2(3 \%)$ & \\
\hline $\begin{array}{l}\text { Hospital other than the primary teaching } \\
\text { hospital (2) }\end{array}$ & $5(36 \%)$ & $32(62 \%)$ & $\begin{array}{l}37 \\
(56 \%)\end{array}$ & \\
\hline
\end{tabular}

Diversity can increase creativity and innovation, result in enhanced group problem solving, increased productivity, ${ }^{22-24}$ and benefit the tripartite mission of academia. ${ }^{25}$ Given our findings, individual institutions may wish to evaluate possible issues of gender inequity, and consider implementing programs to improve the advancement of female AHM. Strategies that address implicit bias in those responsible for hiring and promotion have been useful. ${ }^{26}$ As mentorship and sponsorship are essential for career advancement, and women face greater barriers in accessing mentors, ${ }^{27}$ institutions can improve gender equity by developing mentorship programs for women, with a focus on scholarship and leadership. ${ }^{28,29}$ A focus on effective sponsorship may also be important.

Institutions which have successfully implemented programs to address gender inequality include the University of
Wisconsin, where the Bias Reduction in Internal medicine intervention demonstrated a reduction in gender bias and improved faculty climate for both men and women as well as the total number of female faculty. ${ }^{30}$ Similarly, Stanford University School of Medicine significantly increased female faculty over a 6-year period through providing training for search committees on processes to attract diverse candidates. ${ }^{31}$ Well-designed sponsorship programs have also been effective in advancing women into corporations' upper levels of leadership and can serve as models for sponsorship programs focused on advancing women in leadership positions within academic medicine. ${ }^{32}$

Academic medicine continues to evolve and AHM will be an important component of this development, especially as our survey suggests that most faculty view 
AHM as a career. It is heartening that there are reported roughly equal number of men and women on faculty in AHM. However, our findings of gender inequity in leadership and academic rank suggest that research, faculty development, and interventions to reach gender equity are necessary to move AHM forward.

Acknowledgements: The authors would like to acknowledge the Society of Hospital Medicine, the Johns Hopkins Clinician-Educators Mentoring and Scholarship Program, and the Johns Hopkins General Internal Medicine Methods CORE for their assistance with this study.

Corresponding Author: Carrie Herzke, Department of Medicine, Johns Hopkins University School of Medicine, 600 N. Wolfe Street, Meyer 8-134, Baltimore, USA, MD 21287 (e-mail: cherzke1@jhmi.edu).

\section{REFERENCES}

1. Jagsi R, Guancial EA, Worobey CC, et al. The "gender gap" in authorship of academic medical literature-a 35-year perspective. $N$ Engl J Med. 2006;355(3):281-287.

2. Jolliff L, Leadley J, Coakley E, Sloane R. Women in US academic medicine and science: statistics and benchmarking report 2011-2012. Washington, DC: Association of American Medical Colleges. 2012:1-59.

3. Kaplan SH, Sullivan LM, Dukes KA, Phillips CF, Kelch RP, Schaller JG. Sex differences in academic advancement-results of a national study of pediatricians. $N$ Engl $J$ Med. 1996;335(17):1282-1290.

4. Amrein K, Langmann A, Fahrleitner-Pammer A, Pieber TR, ZollnerSchwetz I. Women underrepresented on editorial boards of 60 major medical journals. Gend Med. 2011;8(6):378-387.

5. Ash AS, Carr PL, Goldstein R, Friedman RH. Compensation and advancement of women in academic medicine: is there equity? Ann Intern Med. 2004; 141(3):205-212.

6. Carr PL, Gunn CM, Kaplan SA, Raj A, Freund KM. Inadequate progress for women in academic medicine: findings from the National Faculty Study. J Womens Health. 2015;24(3):190-199.

7. Burden M, Frank MG, Keniston A, et al. Gender disparities in leadership and scholarly productivity of academic hospitalists. $J$ Hosp Med. 2015; 10(8):481-485.

8. Patton EW, Griffith KA, Jones RD, Stewart A, Ubel PA, Jagsi R. Differences in mentor-mentee sponsorship in male vs female recipients of National Institutes of Health grants. JAMA Intern Med. 2017;177(4):580582.

9. Association of American Medical Colleges, The State of Women in Academic Medicine: The Pipeline and Pathways to Leadership, 20152016. https://www.aamc.org/members/gwims/statistics/489870/ stats16.html. Accessed 7/1/19.

10. Association of American Medical Colleges, U.S. Medical School Applicants and Students 1982-1983 to 2011-2012. https://www.aamc.org/download/153708/data/. Accessed August 23, 2019.

11. Tecco H, McGuinness D, McDowell M, Stotz C, Tam E, Evans B. Women in Healthcare 2017: How does our industry stack up? Rock
Health. https://rockhealth.com/reports/women-in-healthcare-2017how-does-our-industry-stack-up/. Accessed 7/1/19.

12. Hofler LG, Hacker MR, Dodge LE, Schutzberg R, Ricciotti HA. Comparison of women in department leadership in obstetrics and gynecology with other specialties. Obstet Gynecol. 2016;127(3):442.

13. Beasley BW, Simon SD, Wright SM. A time to be promoted: the prospective study of promotion in academia (prospective study of promotion in academia). $J$ Gen Intern Med. 2006;21(2):123-129.

14. Farnan JM, Arora VM. Annals for Hospitalists Inpatient Notes-Gender Equality in Hospital Medicine-Are We There Yet? Ann Intern Med. 2017; 167(6):HO2-HO3.

15. Weaver AC, Wetterneck TB, Whelan CT, Hinami $\mathbf{K}$. A matter of priorities? Exploring the persistent gender pay gap in hospital medicine. $J$ Hosp Med. 2015; 10(8):486-490.

16. Arora VM. It is time for equal pay for equal work for physicians-paging Dr Ledbetter. JAMA Intern Med. 2016;176(9): 1305-1306.

17. Society of General Internal Medicine, SGIM History. https://www.sgim. org/about-us/about/history-and-bylaws. Accessed August 23, 2019.

18. Wachter RM, Goldman L. Zero to 50,000-the 20th anniversary of the hospitalist. N Engl J Med. 2016;375(11):1009-1011.

19. Saint S, Flanders SA. Hospitalists in teaching hospitals: opportunities but not without danger. J Gen Intern Med. 2004;19(4):392-393.

20. Flanders SA, Saint S, McMahon LF, Howell JD. Where should hospitalists sit within the academic medical center? $J$ Gen Intern Med. 2008;23(8): 1269-1272.

21. Freed GL, Dunham KM, Pediatrics RACotABo. Pediatric hospitalists: training, current practice, and career goals. J Hosp Med. 2009;4(3):179186.

22. Nemeth CJ. Dissent, group process, and creativity: The contribution of minority influence. Adv Group Process. 1985;2(1):57-75.

23. Nielsen MW, Alegria S, Börjeson L, et al. Opinion: Gender diversity leads to better science. Proc Natl Acad Sci U S A. 2017;114(8):1740-1742.

24. Woolley AW, Chabris CF, Pentland A, Hashmi N, Malone TW. Evidence for a collective intelligence factor in the performance of human groups. Science. 2010;330(6004):686-688.

25. Smith DG. Diversity's promise for higher education: Making it work. JHU Press; 2015.

26. Sheridan JT, Fine E, Pribbenow CM, Handelsman J, Carnes M. Searching for excellence \& diversity: Increasing the hiring of women faculty at one academic medical center. Acad Med. 2010;85(6):999.

27. Jackson VA, Palepu A, Szalacha L, Caswell C, Carr PL, Inui T. "Having the right chemistry": a qualitative study of mentoring in academic medicine. Acad Med. 2003;78(3):328-334.

28. Mayer AP, Blair JE, Ko MG, et al. Gender distribution of US medical school faculty by academic track type. Acad Med. 2014;89(2):312-317.

29. Sambunjak D, Straus SE, Marušić A. Mentoring in academic medicine: a systematic review. JAMA. 2006;296(9):1103-1115.

30. Carnes M, Devine PG, Baier Manwell L, et al. The Effect of an Intervention to Break the Gender Bias Habit for Faculty at One Institution: A Cluster Randomized, Controlled Trial. Acad Med. 2015;90(2):22 1-230.

31. Ibrahim H, Stadler DJ, Archuleta S, Cofrancesco Jr J. Twelve tips to promote gender equity in international academic medicine. Med Teach. 2018;40(9):962-968.

32. Travis EL, Doty L, Helitzer DL. Sponsorship: A Path to the Academic Medicine C-suite for Women Faculty? Acad Med. 2013;88(10):14141417.

Publisher's Note Springer Nature remains neutral with regard to jurisdictional claims in published maps and institutional affiliations. 